\title{
Effect of dietary calcium on the colonic luminal environment
}

\author{
G V N Appleton, R W Owen, E E Wheeler, D N Challacombe, R C N Williamson
}

\begin{abstract}
Dietary supplementation with calcium may prevent the development of colorectal cancer. This mechanism may be related to fatty acid and bile salt chelation in the small bowel forming non-toxic calcium-soap compounds. Calcium may also act locally or systemically on the colonic mucosa. Faecal concentrations of free fatty acids and free bile acids were measured in 17 Sprague-Dawley rats (weighing $472(39 \mathrm{~g})$ ) whose daily calcium intake had been trebled by enriching the chow and adding calcium lactate $(24 \mathrm{~g} / \mathrm{l})$ to the drinking water. Mean (SEM) faecal concentrations of free bile acids were $33 \%$ less than in 19 controls (1.23 $(0.15)$ v $1.82(0.20) \mathrm{mg} / \mathrm{g} ; \mathrm{p}<0.001)$, whereas free fatty acid concentrations were $117 \%$ higher $(14.68(3.59) v 6.76(2.41) \mathrm{mg} / \mathrm{g} ; \mathrm{p}<0.02)$. The 'direct' effect of calcium was assessed by organ culture of rat colonic explants in three different concentrations of calcium. Crypt cell production rate (measured by a stathmokinetic technique), which was (mean (SEM)) 4.80 $(0.23)$ cells/crypt/h in control medium $\left(\mathrm{Ca}^{2+}=2 \cdot 14 \mathrm{mmol} / \mathrm{l}\right)$, fell by $43 \%$ when calcium concentration was doubled $(p<0.05)$ and by a further $43 \%$ when the concentration was trebled $(p<0.02)$. Calcium binds free fatty acids but not free bile acids intraluminally. Calcium has a direct antitropic action on colonic crypts.
\end{abstract}

Interest in calcium as a chemopreventive agent in colorectal carcinoma began in 1982 when a Scandinavian study showed that the cancer incidence was least in populations consuming a diet rich in diary products despite a high fat intake. ${ }^{1}$ Three years later, Garland's 19 year prospective dietary study on 1954 men from Chicago concluded that a high calcium intake $(>1.5 \mathrm{~g} /$ day $)$ was associated with a $65 \%$ reduction in cancer incidence. ${ }^{2}$ It seems that populations consuming high calcium diets may enjoy a relative freedom from colon cancer.

Experimental work in our laboratory has reinforced some of these findings. Doubling the calcium intake in rats by adding $24 \mathrm{~g} / \mathrm{l}$ to the drinking water halves the yield of colorectal tumours induced by azoxymethane. ${ }^{3}$ There is a corresponding fall in crypt cell production rate in both right and left colon. ${ }^{4}$ Recent data from elsewhere show a similar effect. ${ }^{5}$ Calcium can also modify the behaviour of cell lines and small explants in vitro. The extracellular concentration of calcium is critical in the regulation of proliferation and differentiation of keratinocytes $^{6}$ while calcium reduces proliferation rates in cultured mammary, oesophageal, bronchial, and urothelial cells. ${ }^{78}$
Newmark et al have proposed that potentially toxic bile acids and fatty acids are bound by calcium in the enteric lumen and rendered harmless by the formation of insoluble, nonirritant calcium soaps. ${ }^{9}$ In support of this, the locally damaging effects of both bile acids and fatty acids instilled intrarectally are reversed by giving concomitant calcium gluconate by mouth. ${ }^{11}$ The present two part study was designed to test Newmark's intuitive hypothesis and to investigate the 'direct' effect of calcium. Faecal concentrations of free bile acids and free fatty acids were measured in rats fed different dietary concentrations of calcium. Colonic biopsy specimens were cultured in varying concentrations of calcium, and cytokinetic changes were determined by measuring crypt cell production rate.

\section{Methods}

Adult male Sprague-Dawley rats $(n=42)$ weighing (mean (SD)) 472 (39) $\mathrm{g}$ were used in a two part study on the direct and indirect effects of calcium.

\section{STUDY 1: FAECAL FATS AND BILE ACIDS}

Rats either acted as controls $(n=19)$ and received normal chow and tap water, or they had calcium lactate $24 \mathrm{~g} / \mathrm{l}$ added to the drinking water and ate a calcium enriched chow $(n=17)$ thereby trebling their total daily calcium intake from $0.44 \%$ $\mathrm{w} / \mathrm{w}$ to $1 \cdot 32 \% \mathrm{w} / \mathrm{w}$. After two weeks all animals were sacrificed between 1000 and 1200 hours. A blood specimen was taken by cardiac puncture for measurement of serum calcium. At laparotomy the distal half of the colon was opened, and all faeces were collected. Faecal specimens were immediately deep frozen to $-40^{\circ} \mathrm{C}$. Later, samples were analysed by gas-liquid chromatography for concentrations of free bile acids and free fatty acids according to the method of Alme modified by Owen. ${ }^{12}$

\section{STUDY 2: COLONIC ADAPTATION}

Rats $(n=6)$ were lightly anaesthetised with ether, and a small segment of bowel $(1-2 \mathrm{~cm})$ was excised from the lower descending colon. Each specimen was divided into 15-20 explants $\left(2 \mathrm{~mm}^{2}\right)$ which were established in organ culture in three different concentrations of calcium. Control explants were cultured in standard medium containing calcium $2 \cdot 14 \mathrm{mmol} / 1$. In the other two groups, calcium chloride was added to the medium to double and triple the final concentrations of calcium, which were $4.28 \mathrm{mmol} / \mathrm{l}$ and $6.42 \mathrm{mmol} / 1$. A rocking method of organ culture was used, as previously described. ${ }^{13}$ Vincristine 
Concentrations of faecal bile acids and free fatty acids ( $\mathrm{mg} / \mathrm{g}$ dry wt faeces) (mean (SEM))

\begin{tabular}{llc}
\hline & Control & Added calcium \\
\hline Total bile acids & $1 \cdot 82 \pm(0 \cdot 20)$ & $1 \cdot 23 \pm(0 \cdot 15) \dagger$ \\
Total free fatty acids & $6 \cdot 76 \pm(2 \cdot 41)$ & $14 \cdot 68 \pm(3 \cdot 59)^{\star}$ \\
Saturated fatty acids & $3 \cdot 09 \pm(1 \cdot 45)$ & $6 \cdot 50 \pm(2 \cdot 47)^{\star}$ \\
Unsaturated fatty acids & $2 \cdot 63 \pm(0 \cdot 93)$ & $6 \cdot 07 \pm(2 \cdot 38)^{\star}$ \\
Other fatty acids & $1 \cdot 04 \pm(0 \cdot 34)$ & $2 \cdot 09 \pm(0 \cdot 88)$ \\
\hline
\end{tabular}

$\mathrm{tp}<0 \cdot 001,{ }^{\star} \mathrm{p}<0 \cdot 02$.

$0.5 \mu \mathrm{g} / \mathrm{ml}$ was added to the medium after an 18 hour culture, and explants were removed at 30 minute intervals from $60-180$ minutes thereafter. The number of vincristine-arrested metaphase figures were counted in 15 crypts per specimen and plotted against time after adding vincristine. Crypt cell production rate was calculated by least squares regression analysis of the slope of the line so obtained. ${ }^{14}$

\section{STATISTICAL ANALYSIS}

All results quoted are mean (SEM). Faecal concentrations of fats and bile acids and blood calcium were analysed by the Kruskal-Wallis test and subsequently compared by the MannWhitney U test. Regression lines were compared by Student's $t$ test.

\section{Results}

\section{SERUM CALCIUM}

The threefold difference in calcium intake had no effect on serum calcium concentration. The level was (mean (SEM)) $2.90(0.21) \mathrm{mmol} / \mathrm{l}$ in controls and $2.79(0.15) \mathrm{mmol} / \mathrm{l}$ in rats with the enriched diet.

\section{FAECAL BILE ACIDS AND FATS (Table)}

The faecal content of free (unconjugated) bile acids was $33 \%$ lower in rats receiving the calcium enriched diet than in control rats. By contrast, concentrations of free fatty acids were $117 \%$

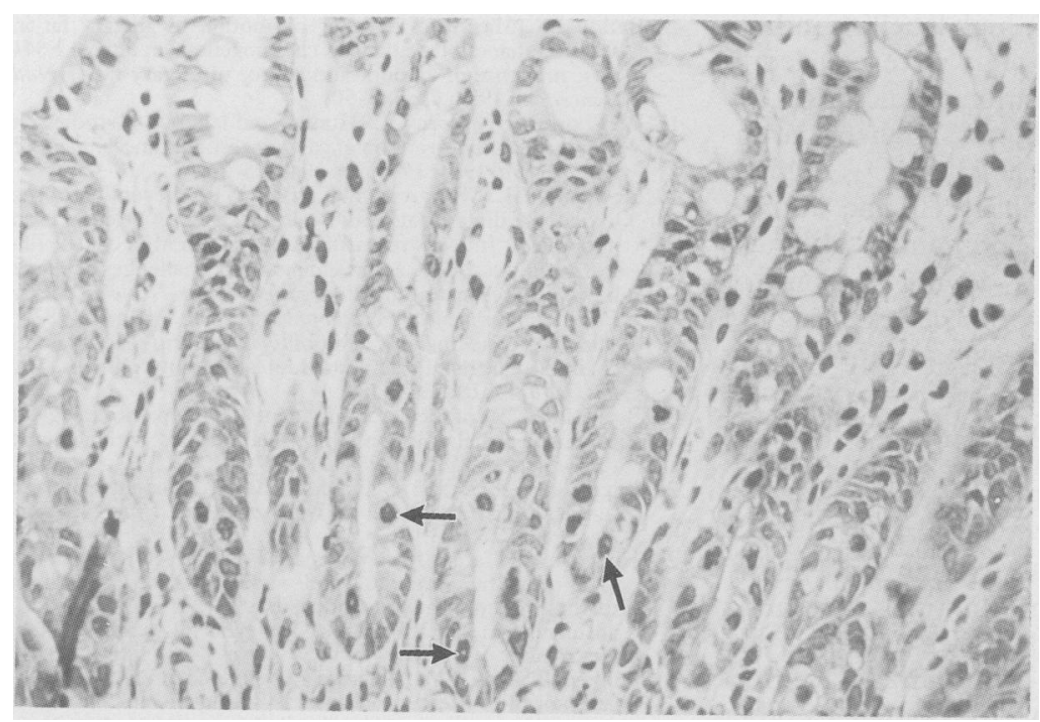

Figure 1: Histological section of colonic mucosa after 21 hour organ culture (three hours after addition of vincristine). Good preservation. Many metaphase figures can be seen arrowed. (Haematoxylin $\mathcal{E}$ eosin, original magnification $\times 200$.) higher in the calcium group. This increase reflected greater excretion of both saturated and unsaturated fats (110-131\%).

\section{ADAPTATION}

After 18 hours of organ culture and a further stathmokinetic period (1-3 hours), colonic mucosal explants were generally well preserved (Fig 1). In 5\% of explants crypt necrosis led to those samples being excluded from the analysis. Overall, counts were made on 29 control explants, 33 from the group with added calcium $2 \mathrm{mmol} / \mathrm{l}$ and 35 from the $4 \mathrm{mmol} / \mathrm{l}$ calcium group. Crypt cell production rate for normal colonic mucosa in the standard medium with no additives was $4.80(0.23)$ cells/crypt/h (Fig 2), which compares well with values in our previous studies. ${ }^{415}$ Doubling calcium concentrations caused a $43 \%$ reduction in crypt cell production rate to $2.75(0.31)$ cells/crypt $/ \mathrm{h}$. Trebling calcium concentrations caused a further $43 \%$ fall to a level $(1.56(0.39)$ cells/crypt/h) that was only $32 \%$ of control values.

\section{Discussion}

Dietary fat, especially unsaturated fat, is a potent co-carcinogen in most animal studies of experimental colorectal cancer. ${ }^{16}{ }^{17}$ Our finding that supplemental calcium more than doubled the output of free fatty acids indicates intraluminal binding of fats. Calcium is a powerful chelator of fats; it binds to them even more strongly than it does to the powerful calcium binding agent ethylenediamine tetra-acetate, especially in a basic $\mathrm{pH}$ environment. ${ }^{18}$ Calcium soaps of fatty acids are known to be relatively insoluble and non-toxic to the colorectal mucosa. ${ }^{19}$ Interaction between supplemental calcium and dietary fat to form calcium-fatty acid soaps in the small bowel may thus explain the lower colorectal tumour yields seen in own study ${ }^{3}$ and in rats on high fat diets, ${ }^{5}$ and the reduction of the colonic proliferative response to bolus delivered corn oil. ${ }^{20}$ Moreover, the increased numbers of mammary neoplasms seen in rats fed high fat diets ${ }^{21}$ is partially reversed by enriching diets with calcium (or vitamin D). ${ }^{22}$

Intracolonic bile acids are also important promoters of experimental carcinogenesis. ${ }^{23}{ }^{24}$ In humans higher faecal concentrations of free bile acids closely correlate with the malignant potential of adenomas ${ }^{25}$ and the incidence of colorectal carcinoma. ${ }^{26}$ Our important finding that calcium lowers potentially toxic colonic concentrations of free bile acids may be explained (as for free fatty acids) by the formation of calcium-bile acid soap complexes. As we found no such compounds in faecal residues, perhaps bile acid soaps that had precipitated in the small bowel did not escape into the colon owing to enteric absorption. Alternatively, chelation of fat by calcium could prevent fat induced stimulation of primary bile acid secretion, with a concomitant reduction in colonic concentrations of secondary bile acids. Few data concerning bile acid soaps are available, but it is known that calcium soaps of fatty acids, especially unsaturated fatty acids such as oleic acid, can be absorbed in the small bowel. ${ }^{27}$ 


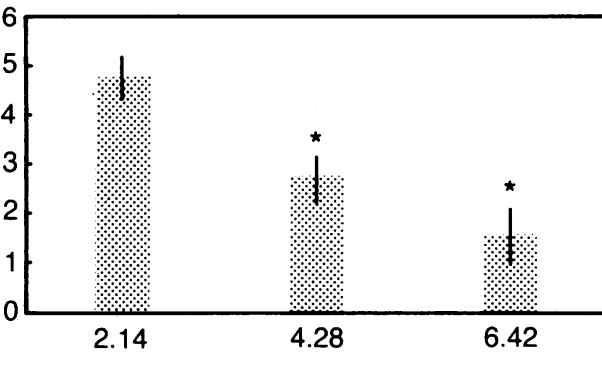

Calcium concentration $(\mathrm{mmol} / \mathrm{l})$

Figure 2: Crypt cell production rate in organ culture. ${ }^{\star} p<0.05$ $\mathrm{v} C a^{2+}=2 \cdot 14, p<0 \cdot 02$ v $C a^{2+}=4 \cdot 28$.

Two recent studies in which colorectal carcinogenesis was stimulated by dietary augmentation with bile acids and fats are in concordance with our data. A threefold increase in dietary calcium in rats receiving parenteral $N$-methyl$N$-nitrosourea failed to reverse the tumour enhancing effect of oral cholic acid. ${ }^{28} \mathrm{By}$ contrast, the tumour promoting effect of a high fat diet was completely reversed by doubling oral calcium intake. ${ }^{5}$ It thus seems probable that calcium does not bind free bile acids in the small bowel or that there is preferential binding of free fatty acids. Some of the data of McSherry $e t a l^{28}$ are controversial, as raised dietary calcium actually enhanced tumour yields in some groups. However, the dose of $N$-methyl- $N$-nitrosourea (and the yield of colorectal tumours) was small in this experiment, and calcium concentrations in the control diet were higher than in ours $(0.56 \%)$. Wargovich emphasises the need for calcium concentrations in control rats to match 'human nutrient density'. ${ }^{29}$ Most commercially available animal feeds have calcium concentrations up to tenfold those in normal human diet. ${ }^{30}$

It is interesting that calcium lowers the birth rate of colonic mucosa in organ culture. A recent (autoradiographic) study of cultured rectal biopsy specimens from 'high risk' patients showed a similar effect: the high labelling indices usually found in these patients were reduced to normal when the concentration of calcium in the culture medium was doubled. ${ }^{31}$ Higher concentrations of calcium (and vitamin $\mathrm{D}_{3}$ ) lead to increased differentiation in a cell line derived from a human colorectal carcinoma, ${ }^{32}$ although malignant epidermal cells do not respond to calcium fluctuations. ${ }^{6}$ It is proposed that calcium prevents loss of cell to cell contact by preserving tight junctions, thus inhibiting cell proliferation..$^{29}$ Any 'direct' effect of calcium is unlikely to be mediated systemically, since serum concentrations were unchanged in this and previous studies in our laboratory. ${ }^{3}$

Although the relative contributions of 'direct' and 'indirect' effects of intraluminal calcium on colonic adaptation and carcinogenesis are unknown, evidence for a direct antitropic effect of calcium on colorectal mucosa (and many other epithelia) is now substantial. Indeed, sufficient animal data are available to justify more trials on human subjects. There are no obvious contra- indications to oral calcium supplements of $1-2 \mathrm{~g} /$ day. Urinary lithiasis is not provoked; in fact it is actually inhibited in patients with a tendency to form oxalate stones. ${ }^{33}$ Calcium may have the added benefit of reducing blood pressure in some hypertensive patients. ${ }^{34}$ The evaluation of colonic cytokinetics has great potential in the identification of 'high risk' patients. Lipkin and Newmark's encouraging results indicating a possible prophylactic role for calcium ${ }^{35}$ may have profound implications for general dietary advice.

1 IARC Working Party. Diet, bowel function, fecal characteristics and large bowel cancer in Denmark and Finland. Nutr Cancer 1982; 4: 5-17.

2 Garland C, Barrett-Connor E, Rossof AH, Shekelle RB, Crique $M H$, Paul O. Dietary vitamin D and calcium and risk of colorectal cancer: a 19-year prospective study in men. Lancet 1985; i: 307-9.

3 Appleton GVN, Davies PW, Bristol JB, Williamson RCN. Inhibition of intestinal carcinogenesis by dietary supplementation with calcium. Brf Surg 1987; 74: 523-5.

4 Appleton GVN, Bristol JB, Williamson RCN. Increased dietary calcium and small bowel resection have opposite dietary calcium and small bowel resection have opposite

5 Pence BC, Buddingh F. Inhibition of dietary-fat promoted colon carcinogenesis in rats by supplemental calcium or vitamin $\mathrm{D}_{3}$. Carcinogenesis 1988; 9: 187-90.

6 Hennings H, Holbrook K. Extracellular calcium regulates growth and terminal differentiation of cultured mouse epithelial cells. In: McKeehan WL, Boynton A, Whitfield $\mathrm{JF}$, eds. Ions, cell proliferation and cancer. New York: Academic Press, 1982: 499-516.

7 Kirk D, Kagawa S, Vener G, Narayan KS, Ohnuke Y, Jones LW. Selective growth of normal adult human epithelial cells in serum-free medium. In vitro 1985; 21: 165-71.

8 McGrath CM, Soule HD. Calcium regulation of normal human mammary epithelial cell growth in culture. In vitro $1984 ; 20: 652-62$.

9 Newmark HL, Wargovich MJ, Bruce WR. Colon cancer and dietary fat, phosphate and calcium: a hypothesis. $\mathcal{F}$ Natl Cancer Inst 1984; 72: 1323-5.

10 Wargovich MJ, Eng VW, Newmark HL, Bruce WR. Calcium ameliorates the toxic effect of deoxycholate on colonic epithelium. Carcinogenesis 1983; 4: 1205-7.

11 Wargovich MJ, Eng VWS, Newmark HL. Calcium inhibits the damaging and compensatory proliferative effects of fatty acids on mouse colon epithelium. Cancer Lett 1984; 23: 253-8.

12 Owen RW, Thompson MH, Hill MJ. Analysis of metabolic profiles of steroids in faeces of healthy subjects undergoing chenodeoxycholic acid treatment by liquid-gel chromatochenodeoxycholic acid treatment by liquid-gel chromatography and gas-liquid chromatograph

13 Challacombe DN, Wheeler EE. Growth of crypt cell nodules in duodenal mucosa during organ culture in vitro. $\mathcal{F}$ Clin Pathol 1985; 38: 1388-93.

14 Goodlad RA, Wright NA. Quantitative studies on epithelial replacement in the gut. In: Titchen DA, ed. Techniques in digestive physiology. Amsterdam: Elsevier Scientific Publishers, 1982: 1-23.

15 Williamson RCN, Rainey JB. The relationship between intestinal hyperplasia and carcinogenesis. Scand $\mathcal{f}$ intestinal hyperplasia and carcinog

16 Reddy BS, Maeura Y. Tumor promotion by dietary fat in azoxymethane-induced colon carcinogenesis in female F 344 rats: influence of amount and source of dietary fat. $\mathcal{F ~ N a t l}$ Cancer Inst 1984; 72: 745-50.

17 Weisburger JH, Horn CL. Human and laboratory studies on the causes and prevention of gastrointestinal cancer. Scand $\mathcal{F}$ Gastroenterol 1984; 19 (suppl 104): 15-26.

18 Newmark HL, Wargovich MJ, Bruce WR. Prevention of the toxicity of dietary fat to the colon by dietary calcium - an hypothesis. In: Mastromarino AJ, Brattain MG, eds. 19721982 - a decade of achievements and challenges in large bowel cancer research. Proceedings of the National Large Bowel Cancer Project Workshop. New York: Praeger, 1982.

19 Graham DY, Sackman JW. Solubility of calcium soaps of longchain fatty acids in a simulated intestinal environment. Dig chain fatty acids in a sim

20 Bird RP. Effect of dietary components on the pathobiology of colonic epithelium: possible relationship with colonic tumorigenesis. Lipids 1986; 21 : 289-91.

21 Rogers AE, Lee SY. Chemically-induced mammary gland tumors in rats: modulation by dietary fat. Prog Clin Biol Res 1986; 222: 255-82.

22 Jacobson EA, James KA, Newmark HL, Carroll KK. Effects of dietary fat, calcium, and vitamin $\mathrm{D}$ on growth of mammary tumorigenesis induced by 7,12-dimethylbenz(a)anthracene in female Sprague-Dawley rats. Cancer Res 1989 ; 49: 6300-3.

23 Rainey JB, Maeda M, Williams C, Williamson RCN. The cocarcinogenic effect of intrarectal deoxycholate in rats is
reduced by oral metronidazole. $B r \mathcal{F}$ Cancer $1984 ; 49: 631-6$.

24 Cohen BI, Raicht RF, Deschner EE, Takahashai M, Sarwai AN, Fazzini E. Effect of cholic acid feeding on N-Methyl NAN, Fazzini E. Effect of cholic acid feeding on N-Methyl $\mathrm{N}$ f Natl Cancer Inst 1980; 64: 573-8. 
25 Hill MJ, Morson BC, Thompson MH. The role of faecal bile acids (FBA) in large bowel carcinogenesis. Br F Cancer 1983; 48: 143.

26 Owen RW, Thompson MH, Hill MJ, Wilpart M, Mainguet P, Roberfroid $M$. The importance of the ratio lithocholic to deoxycholic acid in large bowel carcinogenesis. Nutr Cancer 1987; 9: 68-71.

27 Nicolaysen R. The utilization of calcium soaps in rats. Acta Physiol Scand 1943; 5 (suppl 14-6): 215-8.

28 McSherry CK, Cohen BI, Bokkenheuser VD, Mosbach EH, Winter J, Matoba N, et al. Effects of calcium and bile acid feeding on colon tumors in the rat. Cancer Res 1989; 49: feeding on colon tumors in the rat. Cancer Res 1989; 49:

29 Wargovich MJ. Calcium and colon cancer. $\mathcal{F}$ Am Coll Nutr 1988; 7: 101-6

30 Newmark HL. Nutrient density: an important and useful tool for laboratory and animal studies. Carcinogenesis 1987; 8: $871-5$.
31 Buset M, Lipkin M, Winawer S, Swaroop S, Friedman E. Inhibition of human colonic epithelial cell proliferation in vivo and in vitro by calcium. Cancer Res 1986; 46: 5426-30.

32 Wargovich MJ, Lointer PH. Calcium and vitamin D modulate mouse colon epithelial proliferation and growth characteristics of a human colon tumor cell line. Can $\mathcal{J}$ Physio Pharmacol 1987; 65: 472-7.

33 Goodhart RH. In: Goodhart RH, Shils ME, eds. Modern nutrition in health and disease. Philadelphia: Lea \& Febiger 1980: 1182-92.

34 Grobee DE, Hoffman A. Effect of calcium supplementation on diastolic blood pressure in young people with mild hypertension. Lancet 1986; ii: 703-7.

35 Lipkin M, Newmark H. Effect of added dietary calcium on colonic epithelial cell proliferation in subjects at high risk fo familial colonic cancer. $N$ Engl $\mathcal{F}$ Med 1985; 313: 1381-4. 